\title{
Ultrasound Guided Therapeutic Excisional Vacuum Assisted Biopsy in Fibroadenoma (BIRAD3 Lesions)
}

\author{
Ahmed Mohamed Monib, Ahmed Hassan Soliman, Haneen Ahmed Najeeb \\ Department of Radiology, Ain -Shams University \\ Corresponding author: Haneen A. Najeeb, Mobile: 01008550975; Email: Iphoneiraq93@yahoo.com
}

\begin{abstract}
Background: Our study showed that ultrasound-guided, vacuum-assisted excision can play an efficient role in the diagnosis of benign breast lesions and is a safe and successful alternative treatment of fibroadenomas. Although the breast fibroadenoma is a common benign breast tumor, the treatment and follow-up of these lesions is still debatable. We suggest that UGVAB, which has a well-documented role in the diagnosis of breast lesions, may provide an option for the definitive treatment of breast fibroadenomas.

Objective: The objective of our work was to evaluate ultrasound-guided, vacuum-assisted excision (UGVAE) as an alternative approach in the diagnosis of radiologically benign breast lesions.

Patients and Methods: We prospectively evaluated breast lesions excised using VAB between April -October 2017 at Ain-Shams University /interventionl radiology unit at radiology department, which had a proven diagnosis of fibroadenoma. An informed consent form was obtained from each patient of a total of 25 cases ultrasound-guided VABB using biopsy system. All patients have been subjected to breast ultrasound examination.

Results: Thirteen patients developed hematomas during UGVAE but none needed surgical intervention, while twelve patients pass with no significant hematomas, with $100 \%$ cure rate. None of the patients experienced significant enough pain to require the cessation of the procedure, although $22(88 \%)$ patients reported mild pain and moderate pain (12\%) during procedure. At the two week control, 3(12\%) patients reported taking paracetamol for mild pain. In ten of them (40\%) the pain was strong enough to interfere with sleep.

Conclusion: Vacuum assisted Ultrasound-guided biopsy allows real-time imaging, could be performed without breast compression, and is the preferred method if the lesion is detectable with ultrasound.
\end{abstract}

Keywords: Breast fibroadenomas - Vacuum assisted excisional biopsy - ultrasound-guided, vacuum-assisted excision.

\section{INTRODUCTION}

Breast fibroadenomas (FA) are a common cause of a benign discrete palpable lump in females (1) They are relatively more common in patients aged between 15 and 35 years. They often present as a painless mobile breast lump which are discovered incidentally in the majority of cases by the patients themselves. They can also be discovered during investigations for other breast conditions or during routine screening imaging or examination. They may either remain static, continue to grow or decrease in size. ${ }^{(2)}$.

Sixty nine percent of breast lesions undergoing open surgical biopsy were found to be benign ${ }^{(3)}$ and fibroadenomas (FA) constitute about $50 \%$ of those lesions ${ }^{(4)}$.

Vacuum assisted excisional biopsy (VAB) utilizes large bore needles and can extract larger tissue samples compared to fine needle biopsy and core biopsy. This method leads to a decrease in the rate of negative biopsies as well as a decrease in discordance between the biopsy material and surgical specimen. $\mathrm{VAB}$ is also recommended for lesions located close to the thoracic wall or nipple, since it does not employ a forward moving needle. Benign lesions may need to be removed if they grow, or symptomatic or produce anxiety to the patient. However, surgical excision is costly, since it requires an operating room and sometimes hospitalization. Because it can extract large volumes of tissue, VAB can also be used for the excision of benign breast lesions ${ }^{(5)}$.

Cost-effectiveness has been proved, and this procedure is currently approved for the resection of breast fibroadenomas and other types of benign breast lesions which usually are removed in the operating room. With US-VAB, these patients may avoid going into surgery if the lesion is confirmed to be benign.

As it is a procedure performed under image guiding, the radiologist is professional to deal with this technique ${ }^{(6)}$.

\section{AIM OF THE WORK}

The objective of our work was to evaluate ultrasound-guided, vacuum-assisted excision (UGVAE) as an alternative approach in the diagnosis of radiologically benign breast lesions.

\section{PATIENTS AND METHODS}

We prospectively evaluated breast lesions excised using $\mathrm{VAB}$ during the period between April -October 2017 at Ain-Shams University /interventionl radiology unit which belong to 
radiology department, which had a proven diagnosis of fibroadenoma. An informed consent form was obtained from 25 cases ultrasoundguided VABB using biopsy system. All patients had a previously performed breast ultrasound. The study was approved by the Ethics Board of Ain Shams University.

The parameters which received our attention included size of the lesion as shown in the mammogram or ultrasonogram, a peripheral or central location, or a lump detected in a physical examination. Clinical data including the Breast Imaging Reporting and Data System (BI-RADS) category for the lesions were also recorded. None of the patients had discharge from the nipple. A therapeutic strategy was formulated. Namely, the ultrasound-guided VABB procedures were always managed for the patients whose lesion(s) was (were) probably benign and equal or less than Three in BI-RADS category. Ultrasound-guided VABB was performed mostly in patients who were expected to have a difficult follow-up for lesions $3 \mathrm{~cm}$ or smaller according to the BI-RADS category 3 on ultrasonography, who planned to be pregnant, who felt extremely uneasy from their lesions, whose lesions enlarged during follow-up, and who complained of pains or symptoms. Additionally, this was performed in some patients who refused to undergo excision.

The patients who did not provide informed consent, allergic to the local anesthetic and active chest skin infections on the breast were disqualified from biopsy.

Patients were kept in supine position with the ipsilateral arm raised above the head and with operational area sterilized and draped. An ultrasonic assessment was performed again before the procedure. After local anesthetic consisting of $1 \%$ lidocaine containing a $1: 100,000$ mixture of epinephrine was applied, a 3-5-mm skin incision was made, which serves as the access for the 8gauge probe. Under real-time ultrasound guidance, the probe was positioned beneath the lesion. To make localization accurate, the target lesion was rescanned longitudinally and transversely according to the probe. The needle was rotated at an angle of 45 degrees, to both sides, during the procedure, in order to completely excise the hypoechoic lesion on intraoperative ultrasonography and until normal fat tissue was verified grossly on core pieces. Multiple cores in different directions, as many as needed, were taken sequentially, also under ultrasound guidance. Postprocedure sonography evaluation was made to confirm complete excision. For hemostasis, direct compression was applied for 5 to 10 minutes immediately following the procedure; an elastic bandage was attached, and the patient took bed rest for 6 hours.

Tissue specimens were preserved in $10 \%$ formaldehyde solution and sent to Department of pathology for histopathologic evaluation. The patient could go back to his normal daily life one day post the procedure. The follow-up was carried out with ultrasonography and mammography, at intervals of 3 to 6 months, in order to identify recurrences.

\section{RESULTS}

Table (1): Age (years) distribution of the study group.

\begin{tabular}{|l|c|c|}
\hline \multicolumn{1}{|c|}{ Age (years) } & No. & \% \\
\hline$\leq 35$ years & 12 & $48.0 \%$ \\
\hline$>35$ years & 13 & $52.0 \%$ \\
\hline Total & 25 & $100.0 \%$ \\
\hline Range $($ Mean \pm SD) & \multicolumn{2}{|c|}{$21-51(36.24 \pm 11.21)$} \\
\hline
\end{tabular}

Table (2): Side distribution of the study group.

\begin{tabular}{|l|c|c|}
\hline \multicolumn{1}{|c|}{ Side } & No. & \% \\
\hline Bilateral & 3 & $12.0 \%$ \\
\hline Unilateral & 22 & $88.0 \%$ \\
\hline Single & $19 / 22$ & $86.4 \%$ \\
\hline Two & $3 / 22$ & $13.6 \%$ \\
\hline Total & 25 & $100.0 \%$ \\
\hline
\end{tabular}

Table (3): Lesion (mm) distribution of the study group.

\begin{tabular}{|l|c|c|}
\hline \multicolumn{1}{|c|}{ Lesion (mm) } & No. & \% \\
\hline$\leq 300 \mathrm{~mm}$ & 12 & $48.0 \%$ \\
\hline$>300 \mathrm{~mm}$ & 13 & $52.0 \%$ \\
\hline Total & 25 & $100.0 \%$ \\
\hline & \multicolumn{2}{|c|}{$148.5-588$} \\
Range (Mean \pm SD) & \multicolumn{2}{|c|}{$(324.42 \pm 152.48)$} \\
\hline
\end{tabular}

Table (4): Follow Up distribution of the study group.

\begin{tabular}{|l|c|c|}
\hline Follow Up & No. & \% \\
\hline Lost & 2 & $8 \%$ \\
\hline Yes & 23 & $92 \%$ \\
\hline Total & 25 & $100 \%$ \\
\hline
\end{tabular}

Table (5): Cure distribution of the study group.

\begin{tabular}{|c|c|c|}
\hline Cure & No. & \% \\
\hline $100 \%$ & 25 & $100.0 \%$ \\
\hline$<100 \%$ & 0 & $0.0 \%$ \\
\hline Total & 25 & $100.0 \%$ \\
\hline
\end{tabular}

Table (6): Hematoma distribution of the study group.

\begin{tabular}{|l|c|c|}
\hline \multicolumn{1}{|c|}{ Hematoma } & No. & \% \\
\hline Hematoma & 13 & $52.0 \%$ \\
\hline No hematoma & 12 & $48.0 \%$ \\
\hline Total & 25 & $100.0 \%$ \\
\hline
\end{tabular}


Table (7): Pain during procedure distribution of the study group.

\begin{tabular}{|l|c|c|}
\hline $\begin{array}{c}\text { Pain During } \\
\text { procedure }\end{array}$ & No. & $\%$ \\
\hline No pain & 0 & $0.0 \%$ \\
\hline Mild & 22 & $88.0 \%$ \\
\hline Moderate & 3 & $12.0 \%$ \\
\hline Total & 25 & $100.0 \%$ \\
\hline
\end{tabular}

Table (8): Pain after 2 wks procedure distribution of the study group.

\begin{tabular}{|l|c|c|}
\hline $\begin{array}{c}\text { Pain after 2 wks } \\
\text { procedure }\end{array}$ & No. & \% \\
\hline No pain & 12 & $48.0 \%$ \\
\hline Mild & 3 & $12.0 \%$ \\
\hline Moderate & 10 & $40.0 \%$ \\
\hline Total & 25 & $100.0 \%$ \\
\hline
\end{tabular}

Table (9): Comparison between during procedure and after 2 wks procedure according to pain.

\begin{tabular}{|l|c|c|c|c|}
\hline \multirow{2}{*}{ Pain } & $\begin{array}{l}\text { During } \\
\text { procedure }\end{array}$ & $\begin{array}{l}\text { After } \\
\mathbf{2} \text { wks } \\
\text { procedure }\end{array}$ & \multirow{2}{*}{ x2 } & p-value \\
\hline No pain & $0(0 \%)$ & $12(48 \%)$ & & \\
\cline { 1 - 3 } Mild & $22(88 \%)$ & $3(12 \%)$ & \multirow{2}{*}{30.209} & $<0.001 * *$ \\
\hline Moderate & $3(12 \%)$ & $10(40 \%)$ & & \\
\hline Total & $25(100 \%)$ & $25(100 \%)$ & & \\
\hline
\end{tabular}

\section{DISCUSSION}

Ultrasound-guided vacuum-assisted coreneedle biopsy is a new method that provides the benefits of an operative procedure. For more than one decade, it has been recognized around the world as a low-invasive technique of diagnosing and treating benign breast lesions ${ }^{(7)}$. Importantly, this technique does not require general anesthesia. Moreover, it offers the size of a resulting scar. In the case of a surgery, it is usually around 3-4 cm, while in the case of biopsy it is in the region of $3-5 \mathrm{~mm}^{(8)}$.

Our study has shown that Ultrasound guided vacuum assisted biopsy can serve as an efficient approach for the diagnosis and treatment of presumed benign breast lesions. Ultrasound guided excision of benign breast masses is a safe, effective, and welltolerated minimally invasive procedure for the diagnosis and removal of benign breast masses ${ }^{(9)}$. Ultrasound guided vacuum assisted biopsy may not offer substantial advantages in terms of underestimation of cancer and false-negative results, but it could eliminate the need for multiple insertions (10). It has been estimated that $50 \%$ of women may eventually have some form of fibrocystic breast disease, and 20\% may have fibroadenomas during their lifetime. The persistence of a breast mass, even if non palpable, is the major source of concern. It is also a cause of numerous follow-up visits and a source of repeated referrals to breast surgeons because it is hard to diagnose a hypoechoic lesion detected on Ultrasound without pathologic evaluation. It is worthy to indicate that surgical excision of every presumed benign lesion is costly and has cosmetic implications. Vacuum-assisted biopsy has the advantages of cost-effectiveness and much better cosmetic effects compared to open excision. Accuracy is also an important characteristic of vacuum assisted biopsy, especially in small lesions (11).

We successfully obtained a specimen from the target lesion for all of the lesions in our study. Our results were consistent with those of Parker et al. ${ }^{(12)}$ indicating that the Mammotome rather than core needle biopsy should be used for small lesions, especially those smaller than $1.5 \mathrm{~cm}$, because of its high accuracy in correctly diagnosing small, subcentimeter breast lesions.

Ultrasound guided vacuum-assisted biopsy has an advantage in dealing with multiple presumed benign breast lesions. In our study, bilateral (12\%) of cases had bilateral breast lesions, these lesions were removed under sonographic guidance in Mammotome excision procedures performed during one session.

Among the potential post procedural complications, hematoma was the highest percentage (52\%) occurred during our work due to using large probe,more core in addition to vacuum suction. No reported cases of uncontrolled breast hemorrhage after vacuum-assisted breast biopsy and in turn no transcatheter embolization was needed or recommended. The first reported cases of transcatheter embolization of uncontrolled breast hemorrhage after vacuum-assisted breast biopsy were reported by Goldfischer ${ }^{(13)}$.

In our study, local anesthesia was obtained with $1 \%$ lidocaine containing a 1:100,000 mixture of epinephrine to prevent bleeding. After the removal of the lesion, hemostasis was achieved with 15 minutes of direct manual compression followed by application of a chest wrap with an elastic bandage for 48 to 72 hours, none needed surgical intervention.

A lesion larger than $3 \mathrm{~cm}$ was not a contradiction to vacuum-assisted biopsy. In fact, the maximum tissue volume that can be removed is limited by bleeding, the size of the breast, and the site of the lesion (eg, close to the skin surface results. Our conclusions agree with that of Fine et al. ${ }^{(14)}$ that if the biopsy needle is not rotated at each level, the mass may be bisected and thereby retained, owing to the poor visibility of the lesion once a hematoma is formed ${ }^{(11)}$.

To decrease the residual rate, the vacuumassisted devices should be rotated over an array spanning approximately $180^{\circ}$, especially for lesions larger than $2 \mathrm{~cm}$. Ongoing sonographic assessment of 
the progression of lesion excision and final verification of presumed complete lesion excision should also be performed in real time in both the longitudinal and transverse planes.

We consider the Mammotome to be superior in terms of its accuracy in obtaining samples for the diagnosis of impalpable breast lesions. The smaller the lesions, the more easily it is removed. Furthermore, it should be considered as a viable alternative to much more radical open surgical approaches when faced with the daunting task of removing multiple bilateral presumed benign lesions such as multiple fibroadenomas. We conclude that percutaneous excisional biopsy with a sonographically guided vacuum-assisted device is a safe and effective approach in the accurate diagnosis and complete removal of presumed benign breast masses ${ }^{(\mathbf{1 5})}$.

We do not advocate the use of a vacuumassisted device as a means of achieving resection of breast cancer because there is no validated technique for assessment of the margins of resection ${ }^{(16)}$.

It offers an interesting perspective for avoiding excisional surgery for small breast tumors but requires further confirmational studies when larger probe sizes become available ${ }^{(17)}$.

Finally Sonographically guided vacuumassisted breast biopsy allows for diagnostic accuracy as well as therapeutic management of sonographically visualized benign lesions. It is a minimally invasive procedure compared to surgical intervention, with less patient discomfort, fewer complications, good cosmetic results, and no false-negative results. The indications for resection with sonographically guided vacuum-assisted breast biopsy are a BI-RADS category 2 or 3 lesion and patient request for excision.

\section{CONCLUSION}

The procedures do not deform the breast and cause minimal to no scarring on subsequent mammograms. Complications, such as hematoma and infection are rare, occurring in less than 1 per 1000. Vacuum assisted Ultrasound-guided biopsy allows real-time imaging, can be performed without breast compression, and is the preferred method if the lesion is detectable with ultrasound.

\section{REFERENCES}

1- Carty NJ, Carter C, Rubin C, Ravichandran D, Royle GT and Taylor I (2005): Management of Fibroadenoma of the Breast. Annals of the Royal College of Surgeons of England, 77: 127-130.

2- Smallwood JA, Roberts A, Guyer DP and Taylor I (2011): The natural history of fibroadenoma. Br J Clin Pathol., 95: 614- 622.

3- Clin Radiol. NHS Breast Screening Programme (2009): An Audit of Screen Detected Breast Cancers for the Year of Screening April 2008 to March 2009. https:// associationofbreastsurgery. org. uk/ audit/ nhs- breastscreening-programme-audit/

4- Greenberg R, Skornick Y and Kaplan O (2010): Management of breast fibroadenomas. J Gen Intern Med., 13:640-645.

5- Park HL, Chang SY, Huh JY and Kim JY (2012): Is further diagnostic surgery necessary for the benign papillary lesions. AJR Am J Roentgenol., 177405- 408.

6- Alonso-Bartolomé P, Vega-Bolívar A, TorresTabanera M, Ortega E, Acebal-Blanco M, GarijoAyensa F, Rodrigo I, Muñoz-Cacho P (2004): Sonographically guided $11-\mathrm{g}$ directional vacuum assisted breast biopsy as an alternative to surgical excision: utility and cost study in probably benign lesions. Acta Radiologica., 45(4):390-396.

7- Jayashinghe $Y$ and Simmons PS (2009): Fibroadenomas in adolescence. Curr Opin Obstet Gynecol., 21:402-406.

8- Grady I, Gorsuch $H$ and Wilburn-Bailey S (2008): Long term outcome of benign fibroadenomas treated by ultrasound-guided percutaneous excision. Breast J., 14:275-278.

9- Lacambra MD, Lam CC, Mendoza $P$ et al. (2012): Biopsy sampling of breast lesions: comparison of core needle- and vacuum-assisted breast biopsies. Breast Cancer Res Treat., 132:917-923.

10-Luparia A, Durando M, Campanino P et al. (2011): Efficacy and cost-effectiveness of stereotactic vacuumassisted core biopsy of nonpalpable breast lesions: analysis of 602 biopsies performed over 5 years. Radiol Med., 116:477-488.

11-Ventrella V, Tufaro A, Zito FA et al. (2011): Mammographic characteristics and vacuum-assisted breast biopsy (VABB) of non-palpable breast lesions. Acta Radiol. 52:602-607.

12-Parker SH, Klaus AJ, McWey PJ et al. (2012): Sonographically guided directional vacuum-assisted breast biopsy using a handheld device. AJR Am J Roentgenol., 177:405- 408

13-Goldfischer M (2010): MRI-guided breast biopsy. Applied Radiology,35: 28-33.

14-Fine RE, Israel PZ, Walker LC, Corgan KR, Greenwald LV, Berenson JE et al. (2015): A prospective study of the removal rate of imaged breast lesions by an 11-gauge vacuum-assisted biopsy probe system. Am J Surg., 15(5): 305-315.

15-Hahn SY, Shin JH, Han BK and Ko EY (2011): Sonographically-guided vacuum-assisted biopsy with digital mammography-guided skin marking of suspicious breast microcalcifications: comparison of outcomes with stereotactic biopsy in Asian women. Acta Radiol., 52:29-34.

16-Seror JY, Lesieur B, Scheuer-Niro B, Zerat L, Rouzier R and Uzan S (2012): Predictive factors for complete excision and underestimation of one-pass en bloc excision of non-palpable breast lesions with the Intact ${ }^{\circledR}$ breast lesion excision system. Eur J Radiol., 81:719-724.

17-Diepstraten SC, Verkooijen HM, van Diest PJ et al. (2011): Radiofrequencyassisted intact specimen biopsy of breast tumors: critical evaluation according to the IDEAL recommendations. Cancer Imaging, 11:247-252. 